IRRITABLE BOWEL SYNDROME

\title{
Bacillary dysentery as a causative factor of irritable bowel syndrome and its pathogenesis
}

\author{
L-H Wang, X-C Fang, G-Z Pan
}

Gut 2004;53:1096-1101. doi: 10.1136/gut.2003.021154

See end of article for authors' affiliations

Correspondence to: Professor G-Z Pan, Department of Gastroenterology, Peking

Union Medical College

Hospital, Chinese

Academy of Medical

Sciences, 1 Shuaifuyuan, Beiiing 100730, The

People's Republic of

China; pangz2@

btamail.net.cn

Accepted for publication 6 January 2004
Background and aims: The incidence of irritable bowel syndrome (IBS) or functional bowel disorders (FBD) after bacillary dysentery (BD) has not been extensively evaluated, and little is known of the pathogenesis of post-infective (PI) IBS. Therefore, we investigated the incidence of IBS and FBD in a Chinese patient population who had recovered from BD. To further elucidate its pathogenesis, neuroimmunological changes, including interleukins (IL), mast cells, neuropeptides, and the relationship between mast cells and intestinal nerves, were investigated.

Methods: A cohort study of 295 patients who had recovered from BD (shigella identified from stool in $71.4 \%$ ) and 243 control subjects consisting of patient siblings or spouses who had not been infected with $B D$ were included in the study. All subjects were followed up using questionnaires for 1-2 years to explore the incidence of FBD and IBS, as defined by the Rome II criteria. In 56 cases of IBS (PI and non-PI) from another source, the number of mast cells in biopsy specimens from the intestinal mucosa were stained with antitryptase antibody and counted under light microscopy. Also, the relationship of mast cells to neurone specific enolase (NSE), substance P (SP), 5-hydroxytryptamine (5-HT), or calcitonin gene related peptide positive nerve fibres was observed using double staining with alcian blue and neuropeptide antibodies. In 30 cases of IBS (PI-IBS, $\mathrm{n}=15$ ) taken at random from the 56 cases, expression of interleukin (IL)-1 $\alpha$, IL-1 $\beta$, and IL-1 receptor antagonist (IL-1 ra) mRNAs in intestinal mucosa were identified using reverse transcription-polymerase chain reaction. The above results were compared with 12 non-IBS controls.

Results: In the BD infected cohort, the incidences of FBD and IBS were $22.4 \%$ and $8.1 \%$ (in total)-10.2\% (among those in who shigella were identified) respectively, which were significantly higher $(p<0.01)$ than the incidences of FBD $(7.4 \%)$ and IBS $(0.8 \%)$ in the control cohort. A longer duration of diarrhoea ( $\geqslant 7$ days) was associated with a higher risk of developing FBD (odds ratio $3.49(95 \%$ confidence interval 1.71-7.13)). Expression of IL-1 $\beta$ mRNA in terminal ileum and rectosigmoid mucosa was significantly higher in PI-IBS patients $(p<0.01)$. The number of mast cells in the terminal ileum mucosa in PI-IBS 111.19 (2.83)) and non-PI-IBS patients (10.78 (1.23)) was significantly increased compared with that (6.05 $(0.51)$ ) in control subjects $(p<0.01)$. Also, in the terminal ileum and rectosigmoid mucosa of IBS patients, the density of NSE, SP, and 5-HT positively stained nerve fibres increased $(p<0.05)$ and appeared in clusters, surrounding an increased number of mast cells ( $p<0.01$ compared with controls).

Conclusions: BD is a causative factor in PI-IBS. The immune and nervous system may both play important roles in the pathogenesis of PI-IBS.
$\mathrm{P}$ revious studies revealed that the prevalence of functional bowel disorders (FBD) six months after infectious diarrhoea was $25 \% .{ }^{12}$ A study in the UK indicated that during a one year follow up, the diagnostic rate of irritable bowel syndrome (IBS) was $4.4 \%$ in patients after an episode of bacterial gastroenteritis compared with a rate of $0.3 \%$ in the general population cohort. ${ }^{3}$ Our study provided further evidence that a previous history of dysentery was an important risk factor (odds ratio 3.00; $\mathrm{p}<0.001$ ) of IBS in a randomised population study in Beijing. ${ }^{4}$ However, the prevalence of either IBS or FBD after bacillary dysentery (BD) has not been extensively evaluated.

Also, little is known of the pathogenesis of post-infective IBS (PI-IBS). The fact that only $25 \%$ of patients who have had infectious diarrhoea develop IBS-like symptoms suggests other prerequisites, such as interaction of the nervous and immune systems, are required for IBS symptoms to develop among those infected patients. ${ }^{5}$ It is believed that brain-gut interactions play an important role in the pathogenesis of IBS. Possible connections exist between enteric nerves and immune cellular components. In light of the present literature, it was suggested that mast cells could be a possible candidate connecting the local immune response to the neurohormonal system during acute intestinal infection. ${ }^{67}$
The aims of the present study were: (1) to explore the incidence of PI-IBS and FBD after BD; (2) to identify the intestinal immune response, particularly expression of interleukins (IL) and number of mast cells, in PI-IBS and non-PIIBS patients; and (3) to study the relationship between mast cells and intestinal nerves in the pathogenesis of IBS.

\section{PATIENTS AND METHODS}

Study design/patients

Source I: follow up study

This was a cohort study comprising patients who had suffered from BD and who attended the Dysentery Clinic of the Peking Union Medical College Hospital (PUMCH), from April to October 1998, and their family members who had not been infected with BD. All subjects were adult Chinese, followed up for a period of $1-2$ years, interviewed mainly by

\footnotetext{
Abbreviations: $\mathrm{BD}$, bacillary dysentery; $\mathrm{FBD}$, functional bowel disorder; IBS, irritable bowel syndrome; IL, interleukin; IL-1 ra, interleukin 1 receptor antagonist; PI, post-infective; RT-PCR, reverse transcriptionpolymerase chain reaction; NSE, neurone specific enolase; SP, substance P; CGRP, calcitonin gene related peptide; 5-HT, 5hydroxytryptamine; SA-HRP, streptavidin-horseradish peroxidase; PBS, phosphate buffered saline
} 
telephone by answering a detailed symptom questionnaire. Acute BD was diagnosed by a positive stool culture or on the basis of the following criteria: (1) symptoms of lower abdominal pain, rectal burning, and acute diarrhoea; (2) microscopic examination of faecal effluent revealed polymorphonuclear leucocytes $>15 /$ per high power microscopy, and no protozoa or ova identified; and (3) cured by treatment with antibiotics and no relapse.

In the cohort study, patients' siblings or spouses who did not have episodes of dysentery or acute infectious diarrhoea during the same period were enrolled as controls. Numbers of patients and sources are shown in fig 1.

Source II: subjects involved in mast cell/nerve fibre, and interleukin studies

Patients were from the Gastroenterology Clinic, PUMCH (fig 1). Fifty six cases of diarrhoea-type IBS who fulfilled the Rome II criteria and had acute symptoms were examined for number of mast cells and nerve fibre density in the intestinal mucosa. The group comprised 25 males and 31 females (mean age 43.3 years). Among them, 27 cases with a history of infectious diarrhoea successfully treated with antibiotics were considered to be PI-IBS (shigella were identified from their original stool culture in 11 cases). The other 29 cases without a history of infectious diarrhoea were grouped as non-PI-IBS; patients who had bowel symptoms preceding the onset of IBS were excluded. All subjects underwent the following to exclude an anatomical or biochemical explanation for their symptoms: detailed case history; physical examination; routine blood, urine, and faecal analyses; stool culture; blood chemistry tests; abdominal ultrasonography; and colonoscopy. During colonoscopy, one mucosal biopsy specimen was taken at each of the following locations: $5 \mathrm{~cm}$ proximal to the ileocaecal valve and at the rectosigmoid junction. Specimens were freshly suspended in formalin for
Immunohistochemical study. In 30 cases taken at random from the 56 patients, an additional biopsy specimen was obtained at each location and stored in liquid nitrogen for investigation of IL mRNA expression. There was no difference $(\mathrm{p}>0.05)$ in onset to biopsy interval between PI-IBS (mean 1.32 (SD 0.6) years) and non-PI-IBS ( 1.57 (0.56) years) patients. Twelve subjects (five male and seven female; mean age 43.4 years) who had a negative screening colonoscopy as part of a health examination $(n=3)$, for rectal bleeding finally diagnosed as haemorrhoids $(n=6)$, or for postpolypectomy surveillance $(n=3)$, and who had no bowel symptoms, served as controls for both study groups. The control group underwent the same examination procedure as the study groups and two biopsies at each location were taken during colonoscopy. All biopsies were approved by the examinees.

\section{Questionnaire}

Patients and control subjects in the follow up study answered the same questionnaire, as reported by Neal and colleagues ${ }^{2}$ with minor modifications. Questions concerned the presence of symptoms after the episode of dysentery, such as: abdominal discomfort or pain, form of stool, change in bowel habit, sense of urgency, straining or incomplete evacuation at the passage of stool, passage of slime or mucus, bloating, or feeling of abdominal distension. Question also concerned the patient's general health, previous medical history, and bowel habits a year before dysentery. All questions were followed by "if yes, from what time, on how many days a week, and for how many months a year"?

The majority $(90 \%)$ of patients and their family members were interviewed by telephone, and the remainder by mail. Diagnosis of FBD or IBS was made according to the Rome II criteria. ${ }^{8}$ FBD included other functional bowel disorders as well as IBS (see footnote to table 1).
Source I Followed up series

Patients from dysentery clinic Diagnosed as BD

$n=450$

$\mathrm{n}=450$

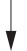

Responders

$\mathrm{n}=329$

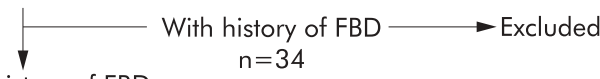

Without history of FBD

$\mathrm{n}=295$

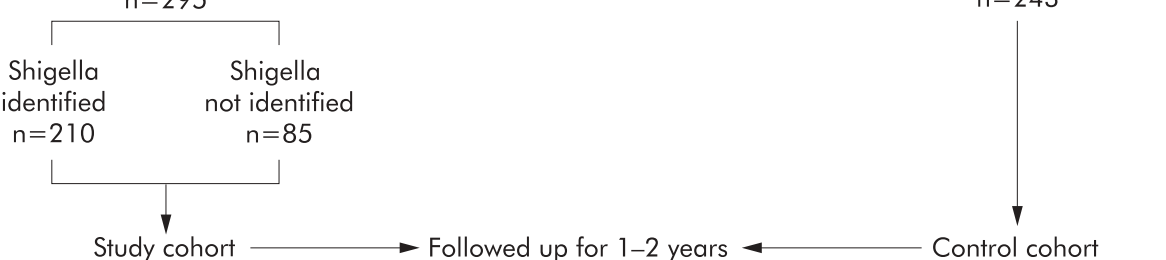

Source II Patients enrolled in mast cell/nerve fibre and IL study

Patients from gastroenterology clinic

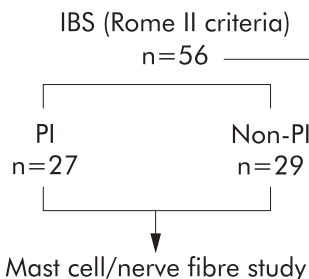

Mast cell/nerve fibre study
Patients siblings or spouse without dysentery or infectious diarrhoea $n=243$ Control cohor (for both study groups)
Figure 1 Flow chart indicating the number of patients and their sources. $B D$, bacillary dysentery; $F B D$, functional bowel disorder; IBS, irritable bowel syndrome; Pl, post-infective. 


\section{Identification of expression of IL mRNAs}

IL- $1 \alpha$, IL- $1 \beta$, and IL- 1 receptor antagonist (IL-1ra) mRNAs were identified as follows. Extraction of RNA from mucosal biopsies by Trizol (Gibco) reagent was based on the procedures provided by the company, and reverse-transcription polymerase chain reaction (RT-PCR) was according to the procedure of Jobin and Gauthier ${ }^{9}$ with minor modifications. The RT-PCR kit was from Boda Company (Beijing, China).

The RT reaction was as the follows: $1 \mu \mathrm{l} d \mathrm{NTP}, 1 \mu \mathrm{l} \mathrm{M}$ MuLV, $1 \mu \mathrm{l} 5 \times \mathrm{M}$-MuLV buffer, $1 \mu \mathrm{l}$ random primer, $0.5 \mu \mathrm{l}$ Rnase inhibitor, and $4 \mu \mathrm{l}$ RNA sample, and then $\mathrm{ddH}_{2} \mathrm{O}$ was added to make a final volume of $20 \mu \mathrm{l}$. The reaction was set at $37^{\circ} \mathrm{C}$ for two hours and then at $95^{\circ} \mathrm{C}$ for five minutes.

For PCR, $4 \mu \mathrm{l}$ of RT product were incubated with $1 \mu \mathrm{l}$ dNTP, $0.5 \mu \mathrm{l}$ Taq polymerase, $5 \mu \mathrm{l} 10 \times$ PCR reaction buffer, $5 \mu \mathrm{l} 15 \mathrm{mM} \mathrm{MgCl}$, and one of the following primers: $4 \mu \mathrm{l}$ IL- $1 \alpha\left(\mathrm{P}_{1}: 5^{\prime}\right.$-GTC TCT GAA TCA GAA ATC CTT CTA TC-3'; $\mathrm{P}_{2}$ : 5'-CAT GTC AAA TTT-CAC TGC TTC ATC C-3', 420 bp product); $4 \mu \mathrm{l}$ IL-1 $\beta$ ( $\mathrm{P}_{1}:$ 5'-ATA AGC CAC TCT ACA-GCT3'; $\mathrm{P}_{2}$ : 5'-ATT GGC CCT GAA AGG AGA GA-3', 436 bp product); $4 \mu \mathrm{l}$ IL-lra ( $\mathrm{P}_{1}: 5^{\prime}$-GGC CTC CGC AGT CAC CTA ATC ACT CT-3'; $\mathrm{P}_{2}: 5^{\prime}$ TAC TAC TCG TCC TCC TGG-AAG TAG AA-3', 521 bp product); or $1 \mu \mathrm{l} \beta$-actin $\left(\mathrm{P}_{1}: 5^{\prime}\right.$ GAA TTC ATG TTT GAG ACC TTC AA3'; $\mathrm{P}_{2}$ : 5'CCG GAT CCA TCT CTT GCTCGA AGT CCA-3', 318 bp product). dd $\mathrm{H}_{2} \mathrm{O}$ was added to make a final volume of $50 \mu \mathrm{l}$. The conditions for the PCR reactions for IL- $1 \alpha$, IL- $1 \beta$, and $\beta$-actin were: $94^{\circ} \mathrm{C}$ for five minutes, then 35 cycles at $94^{\circ} \mathrm{C}$ for 50 seconds, $55^{\circ} \mathrm{C}$ for 50 seconds, and $72^{\circ} \mathrm{C}$ for one minute; re-extension was carried out at $72^{\circ} \mathrm{C}$ for six minutes. The conditions for the PCR reaction for IL-1ra were: $94^{\circ} \mathrm{C}$ for five minutes, 35 cycles at $94^{\circ} \mathrm{C}$ for one $\min , 55^{\circ} \mathrm{C}$ for one minute, and $72^{\circ} \mathrm{C}$ for three minutes; re-extension was carried out at $72^{\circ} \mathrm{C}$ for eight minutes.

After agarose gel electrophoresis of the PCR products, photos of the mRNAs of IL- $1 \alpha$, IL- $1 \beta$, IL-lra, and $\beta$-actin bands were expressed as their complementary cDNAs and were measured by Phoretix ID Advanced software. The intensity of the cDNA for IL- $1 \alpha$, IL- $1 \beta$, or IL-1ra of each sample was normalised by the intensity of $\beta$-actin (relative IL- 1 intensity $=$ IL- 1 intensity $/ \beta$-actin intensity).

\section{Immunohistochemical study of mast cells and nerve fibres}

Rabbit antimast cell tryptase (Maixin Co., Fuzhou, China) was employed for the staining of mast cells in the mucosa. Tissue sections $(4 \mu \mathrm{m})$ were incubated with rabbit antimast cell tryptase overnight at $4^{\circ} \mathrm{C}$. Then, goat antirabbit biotinylated IgG and streptavidin-horseradish peroxidase (SA-HRP) were added for 30 minutes at $37^{\circ} \mathrm{C}$. Staining was developed by diaminebenzidine. All slides were rinsed between each step with phosphate buffered saline (PBS).

The relationship between mast cells and nerve fibres was studied by double staining of mast cells and neuropeptides, according to the method of Stead and colleagues, ${ }^{6}$ with minor modifications. Rabbit antiserum antibodies for neurone specific enolase (NSE), substance $\mathrm{P}$ (SP), calcitonin gene related peptide (CGRP), and 5-hydroxytryptamine (5-HT) were from Maixin Co. (FuZhou, China). In addition to neutral formalin, biopsy samples were further fixed in acetic acid/ethanol (1:9) for eight hours. After tissue sections were stained with alcian blue 8GX (Sigma), rabbit antihuman antibody (NSE, SP, CGRP, or 5-HT) was added overnight at $4^{\circ} \mathrm{C}$ and goat antirabbit biotinylated IgG added for 1030 minutes at $37^{\circ} \mathrm{C}$. Slides were treated with SA-HRP. Staining was developed by 3-amino-9-ethylcarbazole. All slides were rinsed with PBS between each step. PBS was used instead of the primary antibody in the processing of control slides.

Mast cell counting and scoring of neuropeptide staining were performed single blind (that is, the examiner read the slides without knowing the patient's status or diagnosis). Every patient's sample was encoded with a number assigned at random; the code was broken after cell counting. The counting and scoring systems were as follows:

\section{Biostatistical analysis}

The frequencies of all items analysed were compared between the study group and the control group using the $\chi^{2}$ test. Risk factors were explored using regression analysis and analysis of variants.

Cell counts were expressed as the number of cells per field under high power microscopy (mean $(\mathrm{SD})$ ). Positive nerve fibre staining was expressed as the numeric score assessed per field under high power microscopy (mean (SD)). One way ANOVA was used in the comparison. Significant difference was taken as $\mathrm{p}<0.05 ; \mathrm{p}<0.01$ indicated very significant difference.

\section{RESULTS}

\section{The follow up study}

A total of 329 patients participated in the study (response rate $73.1 \%$ ). Thirty four of the responders with a history of FBD were excluded. The remaining 295 cases without a history of FBD were enrolled in the study. Shigella were identified from stool culture in $71.4 \%$ of cases. As the incidence of IBS or FBD in the final analysis was not significantly different between the bacteria identifiable and non-identifiable groups $(\mathrm{p}>0.05)$, data were pooled in the analysis.

In the 295 cases of infectious diarrhoea, the male to female ratio was 1:1.34. Although the male to female ratio in the 243 controls was higher (1.53:1), there was no significant difference in the incidence of FBD or IBS between the sexes $(\mathrm{p}>0.05)$. Mean age of the infectious diarrhoea group was 40.74 (SD 14.94) years compared with 41.26 (14.76) years in the control group. Both groups were comparable in terms of age and economic status.

Incidence of FBD and IBS in infectious diarrhoea and control groups

In the BD group, after a follow up period of $1-2$ years, 66 cases $(22.4 \%)$ were found to have FBD and 24 cases $(8.1 \%$ in total) developed IBS. The incidence of IBS was 10.2\% (24/ 235 ) in patients with shigella infection. In the control group, the incidence of FBD was $7.4 \%$ and of IBS $0.8 \%$, which was significantly lower $(\mathrm{p}<0.01)$ than that in the $\mathrm{BD}$ group.

\section{Risk factors for FBD during infectious diarrhoea} Regression analysis of variants indicated that prolongation of the duration of infectious diarrhoea resulted in an increase in

Table 1 Effect of duration of bacillary dysentery on the incidence of functional bowel disorders (FBD)

\begin{tabular}{lrlll}
\hline Duration (days) & $\mathbf{n}$ & FBD cases $(\%)$ & OR & $95 \% \mathrm{Cl}$ \\
\hline $0-7$ & 125 & $13(10.40)$ & 1.00 & \\
$8-14$ & 104 & $30(31.18)^{\star *}$ & 3.49 & $1.71-7.13$ \\
$\geqslant 15$ & 66 & $23(34.85)^{* *}$ & 4.61 & $2.14-9.91$ \\
\hline
\end{tabular}

Prolongation of the duration of $\mathrm{BD}$ over seven days significantly increased the incidence of FBD $\left({ }^{* *} p<0.01\right)$

FBD includes: IBS, $n=24$; functional diarrhoea, $n=18$; functional abdominal bloating, $n=17$; functional constipation, $n=4$; and unspecified functional bowel disorder, $\mathrm{n}=3$. $\mathrm{OR}$, odds ratio; $95 \% \mathrm{Cl}, 95 \%$ confidence interval. 
Table 2 Interleukin $1 \beta$ mRNA expression in the intestinal mucosa of post-infective irritable bowel syndrome (PI-IBS) and non-PI-IBS patients and controls

\begin{tabular}{llllll}
\hline Location & $\begin{array}{l}\text { PI-IBS } \\
(\mathbf{n}=15)\end{array}$ & $\begin{array}{l}\text { Non-PI-IBS } \\
(\mathbf{n}=15)\end{array}$ & $\begin{array}{l}\text { Control } \\
(\mathbf{n}=12)\end{array}$ & $\mathbf{F}$ & p Value \\
\hline Ileum & $2.73(0.64)$ & $1.38(0.26)$ & $1.50(0.32)$ & 27.06 & $<0.01$ \\
Rectosigmoid & $2.32(0.42)$ & $1.24(0.28)$ & $1.27(0.27)$ & 26.69 & $<0.01$ \\
\hline
\end{tabular}

the incidence of FBD (table 1 ). If the duration of infection exceeded seven days, the patient had a 2.5 -fold increased risk of future development of FBD compared with those whose duration was less than a week. Therefore, we conclude that duration of infectious diarrhoea is an important risk factor in FBD.

Sex or age had no significant effect on the incidence of FBD or IBS in our study (both $\mathrm{p}>0.05$ ).

\section{Expression of IL-mRNAs in intestinal mucosa}

In PI-IBS patients, expression of IL- $1 \beta$ mRNA (expressed as cDNA identified at 436 bp by RT-PCR) in the terminal ileum mucosa or in the rectosigmoid mucosa was significantly higher $(\mathrm{p}<0.01)$ than that in non-PI-IBS patients or in control subjects (table 2, fig 2).

There were no differences in expression of IL- $1 \alpha$ or IL-1ra mRNAs between the IBS groups $(p>0.05)$, or between the IBS and control group $(\mathrm{p}>0.05)$.

\section{Number of mast cells and the relationship between mast cells and nerve fibres in the intestinal mucosa of IBS patients \\ Number of mast cells in the intestinal mucosa of IBS patients and controls \\ The number of mast cells in the mucosa of the terminal ileum in PI-IBS (11.98 (2.83)) and non-PI-IBS (10.78 (1.23)) patients was significantly higher than that $(6.05(0.51))$ in controls $(p<0.01)$ (table 3$)$. There was no significant difference in the number of mast cells in the rectosigmoid mucosa when either IBS group was compared with controls $(p>0.05)$. In either location, there was no significant difference in the number of mast cells in PI-IBS and non- PI-IBS patients $(\mathrm{p}>0.05)$.}
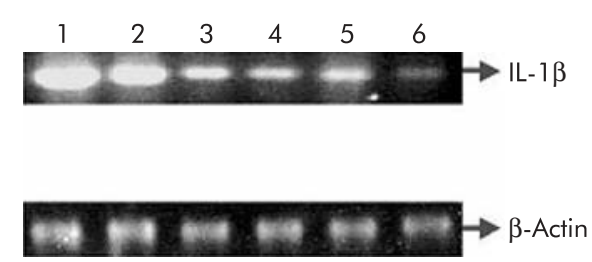

Figure 2 Interleukin $1 \beta$ (IL-1 $\beta$ ) mRNA expression in the intestinal mucosa of irritable bowel syndrome (IBS) patients and controls. Electrophoresis of reverse transcription-polymerase chain reaction products; IL-1 $\beta$ mRNAs are expressed as their complementary cDNAs identified at $436 \mathrm{bp}$. Mucosal specimens were from: lane 1, rectosigmoid junction of a post-infective (PI)-IBS patient; lane 2, terminal ileum of a PI-IBS patient; lane 3, rectosigmoid junction of a non-PI-IBS patient; lane 4, terminal ileum of a non-PI-IBS patient; lane 5,

rectosigmoid junction of a control subject; and lane 6 , terminal ileum of a control subject. Expression of IL-1 $\beta$ mRNAs in PI-IBS patients (as represented in lanes 1 and 2) was significantly higher that that in non-PlIBS patients and controls.
Scores for expression of NSE, SP, 5-HT, and CGRP positive fibres in intestinal mucosa and the relationship between nerve fibres and mast cells in IBS patients

As indicated in table 3, significantly higher scores for expression of NSE, SP, and 5-HT positive fibres in the mucosa of the terminal ileum or at the rectosigmoid junction were found in PI-IBS and non-PI-IBS patients compared with controls $(p<0.05)$. But expression of CGRP positive fibres in the mucosa at either location was not significantly different between either IBS group and the control group ( $p>0.05)$. There was no difference in mucosal expression of NSE, SP, 5-HT, or CGRP positive fibres between PI-IBS and non-PI-IBS patients at either location $(\mathrm{p}>0.05)$.

Using the technique of double staining, it was possible to identify the relationship between mast cells and antibody stained nerve fibres. Nerve fibres stained bright red and appeared in clusters closely surrounding mast cells (fig 3 ). In IBS patients, positively stained nerve fibres around mast cells were significantly increased in density and also mast cells surrounded by those fibres were increased in number in the terminal ileum mucosa compared with controls $(6.73(1.02) \mathrm{v}$ $4.25(0.50) ; 6.84(0.85) \vee 4.28(0.40) ; 6.72(0.81) \vee 4.00$ $(0.63)$; and $6.73(0.82) \vee 4.33(0.54)$, respectively, for NSE, $\mathrm{SP}, 5$-HT, and CGRP stained fibres; all $\mathrm{p}<0.01$ ). However, no difference was observed between the PI-IBS and non-PI-IBS groups $(\mathrm{p}>0.05)$.

\section{DISCUSSION}

Our study in 295 patients recovering from BD with no previous history of FBD indicated that after a follow up period of $1-2$ years, $22.4 \%$ of patients developed symptoms of FBD, and $8.1 \%$ (in total)-10.2\% (among whom shigella were identified) of cases developed IBS-like symptoms, as defined by the Rome II criteria. In the control cohort, consisting of 243 subjects with no episode of BD, and comparable in age, and economic and social status with the study cohort, the development of symptoms of FBD and IBS occurred in only $7.4 \%$ and $0.8 \%$ of cases, respectively, which was significantly lower than that of the study group $(\mathrm{p}<0.01)$. The results of our study are similar to those reported by Neal et al in the UK (FBD 25\%, IBS 7\%), ${ }^{2}$ despite the fact that their patients had food poisoning, chiefly resulting from campylobacter or salmonella infection, and our patients had suffered from $\mathrm{BD}$, the majority of whom were infected with shigella. We also noticed that a higher incidence of FBD tended to occur in patients who had a longer duration of BD. This may be explained by delayed or inappropriate initial treatment, or to a more severe inflammation which resulted in deeper impairment of the underlining nerve fibres. ${ }^{10}{ }^{11}$ It is suggested from the present study that treatment for acute enteric infection should be given initially and efficiently to prevent susceptible cases from subsequent development of FBD or IBS. 
Table 3 Number of mast cells and scores for expression of NSE, SP, 5-HT, and CGRP positive nerve fibres in the intestinal mucosa of post-infective irritable bowel syndrome (PI-IBS) and non-PI-IBS patients and controls

\begin{tabular}{|c|c|c|c|c|}
\hline & $\begin{array}{l}\text { PI-IBS patients } \\
(n=27)\end{array}$ & $\begin{array}{l}\text { Non-PI-IBS } \\
(n=29)\end{array}$ & $\begin{array}{l}\text { Controls } \\
(n=12)\end{array}$ & p Value \\
\hline \multicolumn{5}{|c|}{ Terminal ileum } \\
\hline Mast cell & $11.19(2.83)^{*}$ & $10.78(1.23)^{*}$ & $6.05(0.51)$ & $<0.01$ \\
\hline NSE & $3.59(0.50)^{*}$ & $3.34(0.61)^{*}$ & $2.73(0.90)$ & $<0.05$ \\
\hline $\mathrm{SP}$ & $2.78(0.89)^{*}$ & $2.69(0.85)^{\star}$ & 1.91 (0.70) & $<0.05$ \\
\hline $5-\mathrm{HT}$ & $2.85(0.82)^{*}$ & $2.76(0.91)^{*}$ & $2.09(0.83)$ & $<0.05$ \\
\hline CGRP & $2.26(1.20)$ & $2.14(0.69)$ & 2.09 (1.04) & $>0.05$ \\
\hline \multicolumn{5}{|c|}{ Rectosigmoid } \\
\hline Mast cell & $6.14(0.43)$ & $5.96(0.43)$ & $5.79(0.48)$ & $>0.05$ \\
\hline NSE & $3.37(0.56)^{*}$ & $3.28(0.80)^{*}$ & $2.55(1.21)$ & $<0.05$ \\
\hline SP & $2.89(0.80)^{*}$ & $2.62(1.73)^{*}$ & $2.00(0.77)$ & $<0.05$ \\
\hline $5-\mathrm{HT}$ & $2.74(0.71)^{*}$ & $2.72(0.96)^{*}$ & $2.01(1.13)$ & $<0.05$ \\
\hline CGRP & $2.44(1.05)$ & $2.38(1.01)^{*}$ & 2.27 (1.35) & $>0.05$ \\
\hline $\begin{array}{l}{ }^{*} \mathrm{p}<0.05 \mathrm{co} \\
\mathrm{NSE} \text {, neuro } \\
\text { hydroxytryp }\end{array}$ & $\begin{array}{l}\text { ith control subje } \\
\text { enolase; SP, su }\end{array}$ & ; CGRP, calcit & related pept & 5 \\
\hline
\end{tabular}

The notion that PI-IBS results from an enhanced inflammatory response is further supported by our observation that expression of IL-1 $\beta$ mRNA in the intestinal mucosa was significantly increased in PI-IBS patients. Our observation is similar to that reported by Gwee and colleagues. ${ }^{12}$ They found increased expression of IL-1 $\beta$ mRNA in the rectal mucosa of their patients who developed IBS symptoms at three months after acute gastroenteritis but our study provided evidence for a longer duration of inflammatory response after infection. We also detected an increase in the number of mast cells within the lamina propria in the terminal ileum of our IBS patients. This is consistent with the study of Sullivan and colleagues. ${ }^{13}$ In another study, we found that activation of the mast cell population in the intestinal mucosa was $85 \%$ in IBS patients during the active stage and only $15 \%$ in non-IBS controls $(\mathrm{p}<0.01)$ (to be published). The increase in number and activation of mast cells in the intestinal mucosa and release of its mediators (as represented by IL-1 $\beta$ ) probably reflects enhancement of the immune response to previous inflammation in PI-IBS patients. Release of IL-1 $\beta$ may cause altered physiological function, such as diarrhoea, via its inhibitory effect on intestinal transport of water, electrolytes, and small particles. ${ }^{14}{ }^{15}$ Also, IL- $1 \beta$ is a potent hyperalgesic
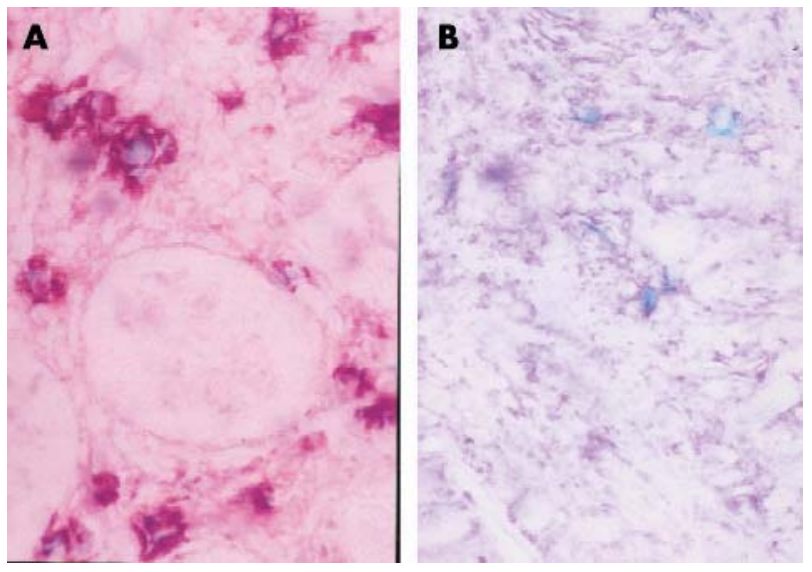

Figure 3 Expression of neurone specific enolase (NSE) stained nerve fibres around mast cells in the mucosa $(\times 1000)$ of the terminal ileum in an irritable bowel syndrome (IBS) patient (A) and a control subject (B). Mast cells stained blue and NSE containing fibres stained red. There is a high density of dark red NSE fibres appearing in clusters around multiple mast cells in the mucosa of the IBS patient compared with very limited staining fibres around the few mast cells in the control subject. agent which may be responsible for hypersensitivity to rectal stimulation in IBS. $^{16}$ Recently, other authors ${ }^{17} 18$ have observed a markedly increased number of $\mathrm{T}$ lymphocytes in the colorectal mucosa of IBS patients, indicating persistence of the immune response in these patients. These observations together with the results of our study on increased numbers of mast cells and higher expression of IL-1 $\beta$ mRNA in PI-IBS patients strongly suggest that activation of the mucosal immune system as an inflammatory response may play an important role in the pathogenesis of PI-IBS.

Our study provides further evidence that a close attachment exists between mast cells and enteric nerves in the intestinal mucosa of IBS patients. Stead and colleagues ${ }^{6}$ indicated over a decade ago that there was a close relationship between mast cells and nerves in human mucosa from the ileum to the sigmoid colon in a number of colonic structural diseases. In the present study, we are able to further demonstrate in IBS patients that a higher density of positively stained nerve fibres (such as NSE, SP, and 5-HT fibres) were closely attached to mast cells in the intestinal mucosa. Also, mast cells surrounded by nerve fibres were significantly increased in number in IBS patients (in both PI-IBS and non-PI-IBS) compared with normal controls $(p<0.01)$. Spiller and colleagues ${ }^{17}$ also identified increased numbers of enteroendocrine cells (including 5-HT containing cell) and T lymphocytes in the rectal mucosa of their PI-IBS patients following campylobacter enteritis. This linkage between immune cells/mast cells and enteric nerves is important as it provides the structural requirement for a dynamic interaction between immune cells and nerves to form integrated neural-immune regulation on gut function in IBS. This was speculated by other investigators recently. ${ }^{19} 20$ The hypothesis is further supported by identification and excitation of $5-\mathrm{HT}_{3}$ receptors on sensory neurones in the rat colon. $^{21}{ }^{22}$ Neuropeptides, such as SP and CGRP, could modulate the activity of mast cells in the opposite direction. ${ }^{23}$ Therefore, factors influencing the nervous system may also participate in the pathogenesis of IBS through this pathway.

In conclusion, our study provides new evidence in support of BD as a causative factor of PI-IBS. Our observation that an enhanced inflammatory response occurred in PI-IBS, and the appearance of clustering of nerves and mast cells in the intestinal mucosa of IBS patients, indicates that the immune system and the nervous system both play important roles in the pathogenesis of PI-IBS. However, we cannot explain the fact that there was also an increased number of mast cells and the same increased expression in positively stained nerve fibres in non-PI-IBS and PI-IBS patients. We do not know 
whether PI-IBS represents a special form of IBS or if the development of all forms of IBS has to undergo the same pathogenetic mechanism. Further studies are needed to elucidate this question.

\section{Authors' affiliations}

L-H Wang, X-C Fang, G-Z Pan, Department of Gastroenterology, Peking Union Medical College Hospital, Chinese Academy of Medical Sciences, Beijing 100730, China

\section{REFERENCES}

1 Gwee KA, Graham JC, McKendrick MW, et al. Psychometric scores and persistence of irritable bowel after infectious diarrhoea. Lancet 1996;347:150-3.

2 Neal KR, Hebden J, Spiller R. Prevalence of gastrointestinal symptoms six months after bacterial gastroenteritis and risk factors for development of the irritable bowel syndrome: postsurvey of patients. BMJ 1997;314:779-81.

3 Rodriguez LAG, Ruigomez A. Increased risk of irritable bowel syndrome after bacterial gastroenteritis: cohort study. BMJ 1999:318:565-6.

4 Pan GZ, Lu SC, Ke MY, et al. Epidemiologic study of the irritable bowel syndrome in Beijing: stratified randomized study by cluster sampling. Chinese Med J 2000;113:35-9.

5 Drossman DA. The functional GI disorders and the Rome II process. In: Drossman DA, et al. The functional gastrointestinal disorders, 2nd edn. USA: Allen Press, 2000:1-30, .

6 Stead RH, Dixon MF, Bramwell NH, et al. Mast cells are closely apposed to nerves in the human gastrointestinal mucosa. Gastroenterology 1989;97:575-85.

7 Gui XY. Mast cells: A possible link between psychological stress, enteric infection, food allergy and gut hypersensitivity in the irritable bowel syndrome. J Gastroenterol Hepatol 1998;13:980-9.

8 Thompson WG, Longstreth GF, Drossman DA, et al. Functional bowel disorders and functional abdominal pain. Gut 1999;45(suppl 2):I143-7.
9 Jobin C, Gauthier J. Differential effects of cell density on 5-lipooxygenase, 5lipooxygenase-activating protein and interleukin-1 beta expression in human neutrophils. Inflammation 1997;21:235-50.

10 Swain MG, Blennerhassett PA, Collins SM. Impaired sympathetic nerve function in the inflammed rat intestine. Gastroenterology 1991;100:675-82.

11 Kubota Y, Petras RE, Ottaway CA, et al. Colonic vasoactive intestinal peptide nerves in inflammatory bowel disease. Gastroenterology 1992;102:1242-51

12 Gwee KA, Collins SM, Read NW, et al. Increased rectal mucosal expression of interleukin $1 \beta$ in recently acquired post-infectious irritable bowel syndrome. Gut 2003;52:523-6.

13 Sullivan M, Clayton N, Breslin NP, et al. Increased mast cells in the irritable bowel syndrome. Neurogastroenterol Motil 2000;12:449-57.

14 Khan I, Collins SM. Interleukin-1 $\beta$ inhibits sodium pump activity in the small intestine of rat. Gastroenterology 1994;106:A523.

15 Kreydiyyeh SI, Haddad JJ, Garabedian BS. Interleukin-1 beta inhibits the intestinal transport of $\left[{ }^{14} \mathrm{C}\right] 3-0$-methylglucose in the rat. Life Sci 1998;63:1913-19.

16 Ferreira SH, Lorenzetti BB, Bristow AF, et al. Interleukin- 1 beta as a potent hyperalgesic agent antagonized by a tripeptide analogue. Nature 1998; 334:698-700.

17 Spiller RC, Jenkins D, Thornley JP, et al. Increased rectal mucosal enteroendocrine cells, T lymphocytes, and increased gut permeability following acute Campylobacter enteritis and in post-dysenteric irritable bowel syndrome. Gut 2000;47:804-11.

18 Chadwick VS, Chen WX, Shu D, et al. Activation of the mucosal immune system in irritable bowel syndrome. Gastroenterology 2002;122:1778-83.

19 Baver O, Razin E. Mast cell-nerve interactions. News Physiol Sci 2000;15:213-18.

20 Wood JD. Neuropathophysiology of irritable bowel syndrome. J Clin Gastroenterol 2002;35(suppl):S1 1-22.

21 Mazzia C, Hicks GA, Clerc N. Neuronal location of 5-hydroxytryptamine 3 receptor-like immunoreactivity in the rat colon. Neuroscience 2003;1 16:1033-41.

22 Kreis ME, Jiang W, Kirkup AJ, et al. Cosensitivity of vagal mucosal afferents to histamine and 5-HT in the rat jejunum. Am J Physiol 2002;283:G612-17.

23 McKay DM, Bienenstock J. The interaction between mast cells and nerves in the gastrointestinal tract. Immunol Today 1994;15:533-8. 


\section{PostScript}

LETTERS

\section{Genetic association between EPHX 1 and Crohn's disease: population stratification, genotyping error, or random chance?}

We read with interest the article by de Jong and colleagues (Gut 2003;52:547-51) reporting studies of genetic associations between DNA polymorphisms in xenobiotic metabolising genes and Crohn's disease (CD). The authors employed a case control study design to test seven polymorphisms in five candidate genes for disease association. Evidence was found for a significant association of a single nucleotide polymorphism (SNP), Tyrl13His $(348 \mathrm{~T}>\mathrm{C})$, in the microsomal epoxide hydrolase l gene (EPHXI), with CD. Homozygosity for the T (Tyr 113) allele was significantly higher in cases than in healthy controls $\left(\chi^{2}=23.7, \mathrm{p}<0.0001\right.$, odds ratio 2.9$)$. The observed frequency of the $\mathrm{T}$ allele in controls was $41 \%$, which is outside the range of frequencies $(58-94 \%)$ reported in other control populations (reviewed in de Jong et al). Its frequency in CD cases was $67 \%$. In view of the strength of reported association, we sought to replicate this observation. We genotyped the Tyrl13His SNP (ref SNP ID rs 1051740) in 307 independent sporadically ascertained cases of CD and 344 ethnically matched healthy control subjects. ${ }^{1}$ This compared with 151 cases and 149 controls typed by de Jong et al. Our study design provided $80 \%$ power to detect a significant difference $(p<0.05)$ in allele frequency of $\geqslant 7.5 \%$ between cases and controls compared with the difference of $26 \%$ observed in the published study. Our power calculations were based on an observed minor (C) allele frequency of $30.2 \%$ in our control cohort, the common ( $\mathrm{T}$ ) allele frequency being $69.8 \%$.

We used TaqMan chemistry (Applied Biosystems) to genotype DNA from cases and controls with an Applied Biosystems 7700 Sequence Detection System. Preoptimised primers and fluorescent probes were obtained from Applied Biosystems (SNP assay ID C 14938 1). All cases and controls were previously genotyped for three confirmed disease susceptibility alleles for $\mathrm{CD}$ (R702W, G908R, Ll007fs) in CARD15, ${ }^{2-4}$ permitting stratification of data by CARD15 mutational status to identify potential gene-gene interactions. ${ }^{5}$ Allele and genotype frequencies were compared between cases and controls using a $\chi^{2}$ test for difference in proportions. Likewise, a $\chi^{2}$ test was used to assess Hardy-Weinberg equilibrium (HWE) across genotypes.

We found no significant differences in allele or genotype frequencies between cases and controls (table 1). Stratification of the data by CARD15 mutation status showed no significant differences in Tyrl13His allele frequencies in $\mathrm{CD}$ cases with none, one, or two CARD15 mutations. Genotypes in our cases and controls were in HWE $(\mathrm{p}>0.5)$.

Case control based studies of genetic association assume that differences in allele frequencies relate directly to the phenotype under investigation, and that no unobserved confounding factors exist which may be attributable to the associated allele. While having greater power than family based studies to detect associations through linkage disequilibrium mapping, case control analysis is susceptible to type I errors (false positives). ${ }^{6}$ One of the most commonly cited explanations for non-replication of genetic associations is stratification, through population admixture, and variability in disease frequencies between and within component subpopulations. However, relatively few instances of this have been clearly established. Stratification may be identified and potentially controlled for by incorporating anonymous genetic markers into the study design. ${ }^{78}$ However, the efficacy of this approach depends on the level of stratification present, and the difference in SNP frequency and disease prevalence in the normal and affected populations. We noted that in de Jong et al the distribution of genotypes in controls for SNP Tyr113His was not in HWE $\left(\chi^{2}=5.67, p=0.017\right)$. It is possible that this may have generated a type I error in their analysis. A degree of population admixture in their control cohort could account for the deviation from HWE and give rise to the observed association between the normally common $\mathrm{T}$ allele (as we observed) and Crohn's disease. Alternative explanations are genotyping error and random chance. We examined the genotype distribution for the seven SNPs tested by de Jong et al and found that in addition to Tyrl13His, the Ile462Val (1506A/G) SNP in CYPlAl was not in HWE $\left(\chi^{2}=7.87, p=0.005\right)$. A recent review of published association studies by $\mathrm{Xu}$ and colleagues ${ }^{9}$ found that $12 \%$ of SNPs tested were inconsistent with HWE in control subjects.

Our findings highlight the value of testing genetic association data for normal genotype distribution, and for rigorous replication of genetic associations with adequate statistical power.

A P Cuthbert, S A Fisher, C M Lewis, C G Mathew

Division of Genetics and Development, Guy's, King's, and St Thomas' School of Medicine, King's College London, Guy's Hospital, London SEl 9RT, UK

J Sanderson

Department of Gastroenterology, St Thomas' Hospital, London SEI 7EH, UK

A Forbes

St Mark's Hospital, Northwick Park, Watford Rd, Harrow, Middlesex HAl 3UJ, UK

Correspondence to: Professor C G Mathew, Department of Medical and Molecular Genetics, GKT School of Medicine, 8th floor Guy's Tower, London SE1 9RT, UK; christopher.mathew@kcl.ac.uk

\section{References}

1 Cuthbert AP, Fisher SA, Mirza MM, et al. The contribution of NOD2 gene mutations to the risk and site of disease in inflammatory bowel disease. Gastroenterology 2002;122:867-74.

2 Ogura Y, Bonen DK, Inohara N, et al. A frameshift mutation in NOD2 associated with susceptibility to Crohn's disease. Nature 2001:411:603-6.

3 Hugot JP, Chamaillard $M$, Zouali $\mathrm{H}$, et al. Association of NOD2 leucine-rich repeat variants with susceptibility to Crohn's disease. Nature 2001;411:599-603.

4 Hampe J, Cuthbert A, Croucher PJ, et al. Association between insertion mutation in NOD2 gene and Crohn's disease in German and British populations. Lancet $2001 ; 357: 1925-8$.

5 Mirza MM, Fisher SA, King K, et al. Genetic evidence for interaction of the $5 \mathrm{q} 31$ cytokine locus and the CARD1 5 gene in Crohn disease. Am J Hum Genet 2003;72:1018-22.

6 Cardon LR, Palmer U. Population stratification and spurious allelic association. Lancet 2003;361:598-604.

7 Pritchard JK, Rosenberg NA. Use of unlinked genetic markers to detect population stratification in association studies. Am J Hum Genet 1999;65:220-8

8 Hoggart CJ, Parra EJ, Shriver MD, et al. Control of confounding of genetic associations in stratified populations. Am J Hum Genet 2003:72:1492-504.

9 Xu J, Turner A, Little J, et al. Positive results in association studies are associated with departure from Hardy-Weinberg equilibrium: hint for genotyping error? Hum Genet 2002;111:573-4.

Table 1 Allele and genotype frequencies between cases and controls

\begin{tabular}{llllllll}
\hline & & \multicolumn{5}{c}{ Tyr113His genotype } & \\
\cline { 5 - 6 } \cline { 5 - 6 } Phenotype & & & $\begin{array}{l}\text { T/T } \\
\text { Tyr/Tyr }\end{array}$ & $\begin{array}{l}\text { T/C } \\
\text { Tyr/His }\end{array}$ & $\begin{array}{l}\text { C/C } \\
\text { His/His }\end{array}$ & $\begin{array}{l}\text { Tyr allele } \\
\text { frequency (T) }\end{array}$ \\
\hline Controls & & 344 & 167 & 146 & 31 & $69.8 \%$ \\
CD & ALL & 307 & 155 & 127 & 25 & $71.2 \%$ \\
CD & O CARD15 DSAs & 202 & 99 & 83 & 20 & $69.6 \%$ \\
CD & 1 CARD15 DSA & 69 & 33 & 33 & 3 & $71.7 \%$ \\
CD & 2 CARD15 DSAs & 20 & 12 & 7 & 1 & $77.5 \%$
\end{tabular}

DSAs, disease susceptibility alleles; CD, Crohn's disease.

\section{Use of cyclosporin in pregnancy}

Cyclosporin has been established in the management of steroid resistant severe ulcerative colitis. We read the letter by Dor and Blanshard (Gut 2003;52:1070) regarding the severe side effects of cyclosporin used in a patient with steroid resistant severe ulcerative colitis after undergoing emergency Caesarean section. We would like to report our experience of a pregnant patient with steroid resistant severe distal ulcerative colitis in whom remission was induced with cyclosporin. She delivered a healthy baby at 34 weeks. 
A 36 year old woman presented for the first time with a five week history of bloody diarrhoea and mucus discharge in the 12th week of her first pregnancy. Ulcerative colitis was confirmed on flexible sigmoidoscopy and histology. She was started on mesalazine (Pentasa) $1 \mathrm{~g}$ twice daily orally and Pentasa enema was added subsequently. She failed to respond well to oral prednisolone $(40-60 \mathrm{mg}$ daily) for five weeks or to subsequent intravenous prednisolone given for a further two and a half weeks. Azathioprine (oral $150 \mathrm{mg}$ daily) was also added. Repeat sigmoidoscopy confirmed severe distal colitis with ulceration. At the $23 \mathrm{rd}$ week of pregnancy, she was started on intravenous cyclosporin $(2 \mathrm{mg} / \mathrm{kg})$ with careful monitoring of serum levels. Significant improvement was noted in two weeks, after which cyclosporin was changed to the oral route. Steroids were gradually tapered to $2.5 \mathrm{mg}$ daily. At 34 weeks she underwent an emergency Caesarean section because of antepartum haemorrhage and a healthy baby girl (birth weight $2.07 \mathrm{~kg}$ ) was delivered. Two weeks later, cyclosporin was weaned off after minimal rise of serum creatinine that coincided with high serum cyclosporin levels. Her serum creatinine normalised four weeks later. She and baby remained well on azathioprine and mesalazine 14 weeks after delivery.

Intravenous cyclosporin induced remission in our pregnant patient who had failed to respond to high dose oral and intravenous prednisolone. Colectomy and the associated potential complications in pregnancy were avoided. There is only one other case report in the literature ${ }^{1}$ where cyclosporin was used in similar circumstances. While we would agree that cyclosporin should be used cautiously in pregnancy, our positive experience, and that of Bertschinger and colleagues, ${ }^{1}$ suggests that cyclosporin may induce remission and avoid colectomy during pregnancy.

A Jayaprakash, S Gould, A G Lim Department of Gastroenterology, Epsom General Hospital, Epsom, Surrey, UK

H A Shehato

Department of Obstetric Medicine, Epsom General Hospital, Epsom, Surrey, UK

Correspondence to: $\operatorname{Dr}$ A Jayaprakash, 130 Farriers Road, Epsom KT17 1NS, UK; jaypy@hotmail.com

\section{Reference}

1 Bertschinger $\mathbf{P}$, Himmelmann A, Risti $B$, et al Ciclosporin treatment of severe ulcerative colitis during pregnancy. Am J Gastroenterol 1994;89:931-3.

\section{Is symptom control the correct end point for proton pump inhibitor treatment in Barrett's oesophagus?}

We have recently reported that abnormal acid reflux persists in up to $50 \%$ of patients with long segment Barrett's oesophagus, despite good control of symptoms of gastro-oesophageal reflux disease (GORD) with proton pump inhibitor (PPI) therapy. ${ }^{1}$ The critical question is whether such persistence of abnormal acid reflux alters the risk of progression to adenocarcinoma. We investigated this issue by studying cellular proliferation and expression of cyclin Dl, which is an important marker of neoplastic progression, ${ }^{23}$ in patients with Barrett's oesophagus on PPI therapy.

A prospective cross-sectional survey of 20 patients with long segment Barrett's oesophagus (defined as a length $\geqslant 3 \mathrm{~cm}$ and presence of specialised intestinal epithelium containing alcian blue staining goblet cells) was conducted. In all cases, GORD symptoms had been well controlled with PPI therapy (omeprazole $\mathrm{n}=13$ patients, median dose $20 \mathrm{mg}$ (range 10-40); lansoprazole $\mathrm{n}=5$, $30 \mathrm{mg}$; or rabeprazole $\mathrm{n}=2,20 \mathrm{mg}$ ). Patients had received PPI therapy for a median duration of 30 months (12-66). Oesophageal manometry, 24 hour ambulatory pHmetry, and Bilitec 2000 monitoring were conducted on all patients, without interruption of their usual PPI therapy. Representative endoscopic biopsy specimens of Barrett's oesophagus from each patient were studied for expression of cyclin Dl protein (primary antibody 1:50 dilution; Novocastra Lab) and Ki-67 protein (primary antibody 1:75; Dako Lab), by standard immunohistochemistry. The histopathologist was blinded to clinical information. A proliferative index was computed for each patient by scoring the percentage of Ki-67 labelled specialised columnar epithelial cells, as previously described. ${ }^{4}$ Cyclin Dl expression was semi quantitatively assessed. The mean percentage of positive cells in areas of intestinal-type specialised columnar epithelium was assigned to one of three categories: $0,<5 \%$; $1,5-50 \%$; or $2,>50 \%$. The intensity of cyclin Dl immunostaining was scored as: weak $=1$, moderate $=2$, or intense $=3$. The percentage category of positive cells and staining intensity were multiplied to produce a weighted score for each patient. All cases with weighted scores $\geqslant 1$ were designated positive.

Despite PPI therapy and absence of GORD symptoms, pHmetry detected abnormal acid
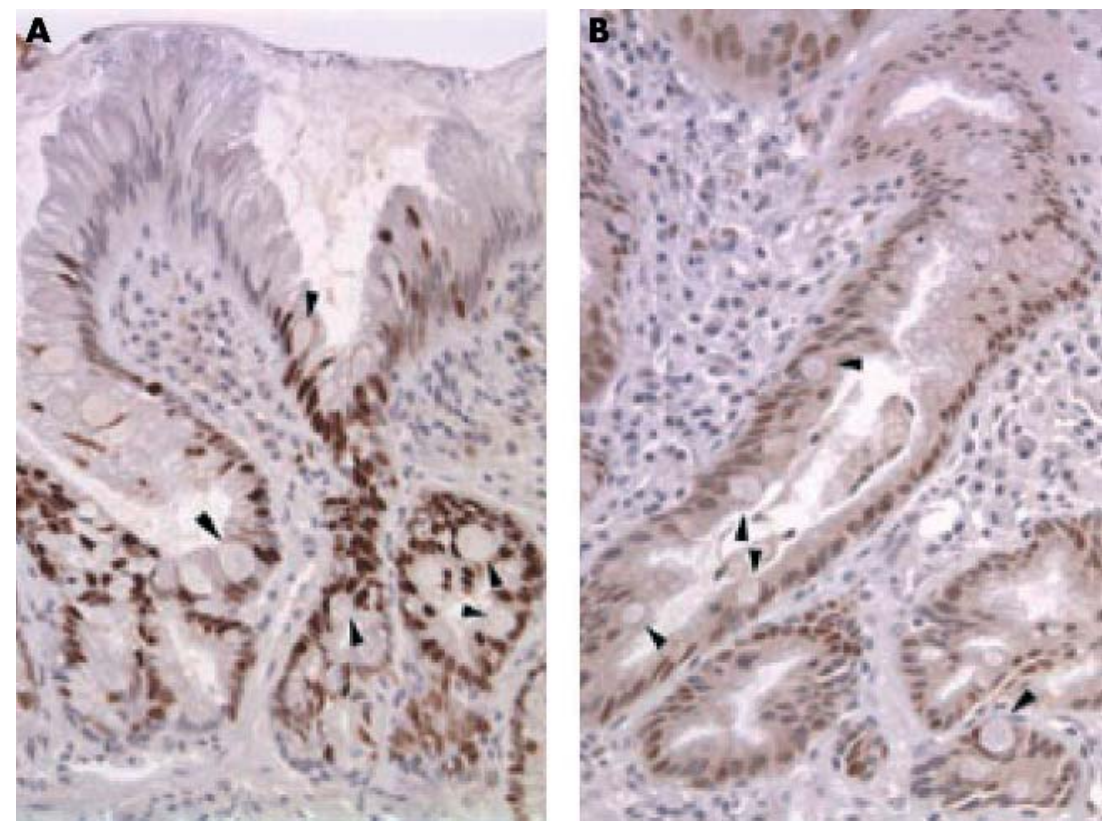

Figure 1 (A) Ki-67 immunoreactive cells are localised at the base of the crypts and glandular zones in specialised intestinal-type columnar epithelium. Arrowheads indicate some goblet cells (original magnification $200 \times$ ). (B) Specialised intestinal-type columnar epithelium exhibits moderate nuclear cyclin DI staining in the majority of epithelial cells lining the crypts (weighted score 4). Arrowheads indicate some goblet cells (original magnification $200 \times$ ). reflux in nine $(45 \%)$ patients $(\mathrm{pH}<4$ for (median) $19.2 \%$ (range $4.6-32.1$ ) of 24 hours DeMeester score 49.5 (20.2-109.8)). The the normal range $(\mathrm{pH}<4$ for $\leqslant 4.5 \%$ of 24 hours). Proliferative indices (mean (SD)) for patients with abnormal acid reflux and those with normal acid reflux were similar (36.5 (8.7) v 37.4 (5.5), respectively; $\mathrm{p}=0.3$ ). Cyclin Dl expression was positive in seven $(78 \%)$ patients with abnormal acid reflux and (64\%) patients with normal aci ( (range 2-6)) for patients with abnormal acid reflux and those with normal acid reflux.

These data imply that the risk of neoplastic progression was independent of the status of examined the association between acid reflux and bile reflux. Absorbance $\geqslant 0.14$ for $\leqslant 1.8 \%$ sidered the normal this study. Despite PPI therapy, abnormal bile reflux was detected in $12(60 \%)$ patients, including six $(55 \%)$ with normal acid reflux six $(66 \%)$ with abnormal acid reflux (absorbance $\geqslant 0.14$ for $17.4 \%$ (3.5-63.7)). Such persistent bile reflux may explain the similarity in expression of Ki-67 or cyclin Dl in the two groups with different control of acid eflux.

In contrast with PPI therapy, antireflux surgery that is successful in controlling acid reflux also controls bile reflux ${ }^{5}$ Following indices in surface epithelial cells and crypts of Barrett's oesophagus are significantly lower compared with a failed procedure. ${ }^{6}$ In the light of the present data, we propose the need for a novel clinical trial of PPI therapy versus antireflux surgery. Patients who are randomised to PPI therapy should undergo control of acid reflux by PPI therapy. We also 
serial $\mathrm{pH}$ and Bilitec monitoring, with appropriate therapeutic modification to achieve predetermined end points. Patients who are randomised to laparoscopic fundoplication should have additional PPI therapy, as required, to achieve the same end points. Outcomes should be measured by standard serial endoscopic assessment and also by examination of a panel of molecular and cellular markers that is important in the pathogenesis of Barrett's adenocarcinoma.

A I Sarela, C S Verbeke, C Pring, P J Guillou University of Leeds School of Medicine, Leeds, UK

Correspondence to: Mr A Sarela, B 37, Clarendon Wing, Department of Surgery, The General Infirmary at Leeds, Leeds LS1 3EX, UK; a.sarela@leeds.ac.uk

\section{References}

1 Sarela Al, Hick DG, Verbeke CS, et al. Persistent acid and bile reflux in asymptomatic patients with Barrett's esophagus on proton pump inhibitor therapy. Arch Surg 2004 (in press).

2 Bani-Hani K, Martin IG, Hardie U, et al. Prospective study of cyclin DI overexpression in Barrett's esophagus: association with increased risk of adenocarcinoma. J Natl Cancer Inst 2000;92:1316-21.

3 Gimenez A, Minguela A, de Haro LM, et al. DNA ploidy status and proliferative activity as markers of malignant potential in Barrett's esophagus: flow cytometric study using routinely paraffinembedded tissue. World J Surg 2000;24:72-7.

4 Sarela Al, Verbeke CS, Ramsdale J, et al. Expression of survivin, a novel inhibitor of apoptosis and cell cycle regulatory protein, in pancreatic adenocarcinoma. $\mathrm{Br} J$ Cancer 2002;86:886-92

5 Stein HJ, Kaver WK, Feussner $\mathrm{H}$, et al. Bile reflux in benign and malignant Barrett's esophagus: effect of medical acid suppression and nissen fundoplication. J Gastrointest Surg 1998:2:333-41.

6 Chen LQ, Hu CY, Gaboury L, et al. Proliferative activity in Barrett's esophagus before and after antireflux surgery. Ann Surg 2001;234:172-80.

\section{Improving hepatitis $\mathrm{C}$ services across the UK: response to a walk-in HCV testing service}

The Department of Health (DH) estimates that approximately $0.4 \%$ of the UK population are chronically infected with hepatitis C virus (HCV) (that is, 200000 people). As few as $10 \%$ of these individuals, who are at risk of end stage liver disease, are thought to be aware of their infection. Clearly action is required to identify and treat these patients with current drugs (pegylated interferons and ribavirin) that can cure over $50 \%$ of infected patients.

The UK voluntary sector have responded to the government identified need for more public information about HCV by organising a hepatitis C awareness day. We took advantage of the publicity around hepatitis $\mathrm{C}$ awareness day to assess the value of a walk-in HCV testing clinic.

Our clinic was held over four days (4-7 July 2003) and was widely publicised in the local press and television. Patients who wished to be tested were invited to attend a clinic in the Minor Injuries Unit at St Bartholomew's Hospital in the City of London. The clinic was manned between $8 \mathrm{am}$ until $1 \mathrm{lam}$ for counselling and informed testing (hepatitis C antibody test and liver function tests). Results were available the next day and patients were informed in person 24 hours later.
Nineteen people attended and two were infected. One of these patients had been lost to follow up due to non-attendance at a local liver clinic 12 years ago.

Open access confidential hepatitis $\mathrm{C}$ testing clinics may play an important role in encouraging people to come forward for HCV testing and may facilitate public education about this important treatable infection. However, these clinics are labour intensive and, in our experience, unlikely to provide a cost effective solution to the identification of people with this treatable, sometimes fatal, infection.

R F C D'Souza, M J Glynn, E Alstead, G R Foster Hepatobiliary Group, Barts and The London, Queen Mary's School of Medicine and Dentistry, London, UK

I Ushiro-Lumb

Department of Virology, Barts and The London, Queen Mary's School of Medicine and Dentistry, London, UK

Correspondence to: Professor G R Foster Hepatobiliary Group, Department of Gastroenterology, DDRC, Turner St, London El 2AD UK; g.r.foster@qmul.ac.uk

Conflict of interest: Dr Foster acts as a consultant to companies who sell drugs for the treatment of viral hepatitis and has received research funding from such companies. He has received fees from companies who market antiviral therapeutics.

\section{Influence of mode of delivery on gut microbiota composition in seven year old children}

Intestinal microbiota development begins immediately following birth. ${ }^{1}$ The composition of the infant's evolving microbiota is initially defined by the mother, the source of the newborn's first microbial inoculum. Colonising bacteria rapidly adapt to breast milk and epithelial mucins as sources of nutrients.

The prevalence of caesarean section delivery in Western countries is increasing. Caesarean born babies are deprived of contact with the maternal/vaginal microbiota and the first exposure is characterised by a lack of strict anaerobes and the presence of facultative anaerobes such as Clostridium species. ${ }^{2}$ Caesarean born infants have a more slowly diversifying microbiota, with differences reported from normally born infants, even after six months of age. Aberrancies in early microbiota acquisition can affect immunophysiological development with a heightened disease risk. ${ }^{23}$ This study assessed microbiota composition in seven year old children and compared the respective effects of normal delivery and caesarean section.

Table 1 Numbers of faecal bacteria (log 10 number of bacteria/g faeces) and total serum $\lg E$ concentration, and number of children with asthma or atopic dermatitis among seven year old children with a history of normal birth or caesarean section

\begin{tabular}{lccl}
\hline $\begin{array}{l}\text { Parameter (concn of specific microbe } \\
\text { or total lgE) }\end{array}$ & Normally delivered & Caesarean born & p Value \\
\hline Clostridia & $9.29(9.06-9.51)$ & $8.83(8.6-9.06)$ & 0.0055 \\
Bifidobacteria & $10.32(10.13-10.5)$ & $10.29(9.99-10.59)$ & 0.87 \\
Total bacteria & $11.56(11.46-11.7)$ & $11.59(11.5-11.68)$ & 0.61 \\
Lactobacilli/enterococci & $9.07(8.85-9.3)$ & $9.05(8.86-9.2)$ & 0.85 \\
Bacteroides & $9.95(9.67-10.24)$ & $9.84(9.52-10.17)$ & 0.63 \\
Total lgE & $79(16-255)$ & $65(25-160)$ & 0.85 \\
\hline
\end{tabular}

Values are median (interquartile range).
In all, 60 seven year old children were randomly selected from Southwestern Finland, representing caesarean and vaginal deliveries. ${ }^{4}$ The children were invited to attend a clinical examination, including skin prick testing and determination of serum total and antigen specific IgE antibodies. Perinatal data were derived from hospital medical records. Questionnaires were completed by the parents to verify a history of allergic symptoms.

Faecal samples were produced at clinical examination and frozen at $-70^{\circ} \mathrm{C}$ for microbiota assessment. Faecal microbiota profiles were determined using the culture independent fluorescent in situ hybridisation method. Probes specific for bifidobacteria, lactobacilli/enterococci, bacteroides, clostridia, and total bacterial numbers were applied. ${ }^{5}$ Written informed consent was obtained from parents and the study was approved by the ethics committee of the university.

Of the study population, 31 children had been delivered by caesarean section and 29 by vaginal delivery. At seven years of age, significantly higher numbers of clostridia were found in children delivered vaginally compared with caesarean born children $(\mathrm{p}=0.0055) \quad($ table 1$)$. No differences were observed in other faecal bacteria or total numbers of bacteria (table 1 ).

Children with asthma diagnosed by a physician $(n=6)$ had lower numbers of clostridia in their faecal specimens while healthy children $(n=54)$ had higher clostridial numbers.

Early colonisation guides subsequent microbiota development which may later impact on health, to the extent of predisposing some infants towards specific diseases. ${ }^{3}$ Bifidobacteria are considered useful for health promotion. Reported effects are related to the individual "balance" of the gut microbiota and prevention of aberrancies within the gastrointestinal tract. Clostridia are generally considered harmful toxin producing species causing diarrhoea and food poisoning.

Our results show that bifidobacterial levels in the faeces of cohort children were comparable at seven years of age, independent of the mode of delivery at birth, while numbers of clostridia were significantly higher in normally born children seven years after birth.

Differences in neonatal gut microbiota, in particular the balance between Bifidobacterium species and Clostridium species, have been reported to precede heightened production of antigen specific IgE antibodies, a hallmark of the atopic responder type. ${ }^{1}$ Such differences may be related to external environmental 
factors (for example, mode of delivery and early feeding practices). The results of this study, showing that clostridial numbers in normally born children seven years after delivery are significantly higher than in caesarean born children, demonstrate that abnormal development of the intestinal microbiota reported following caesarean section delivery may continue even beyond infancy. These findings call for further assessment of microbiota composition throughout childhood when dietary interventions may still offer a rational means of health improvement. It is of importance to characterise the optimal clostridial numbers and species composition at different ages following normal and caesarean delivery.

S Salminen

Department of Biochemistry, University of Turku 20014 Turku, Finland

G R Gibson, A L McCartney

Food Microbial Sciences Unit, School of Food Biosciences, University of Reading, Reading, UK

E Isolauri

Department of Paediatrics, University of Turku, 20014 Turku, Finland

Correspondence to: Professor S Salminen, Functional Foods Forum, University of Turku, 20014 Turku Finland; seppo.salminen@utu.fi

\section{References}

1 Guarner F, Malagelada J-R. Gut flora in health and disease. Lancet 2003:360:512-19.

2 Grönlund MM, Lehtonen OP, Eerola E, et al. Fecal microflora in healthy infants born by different methods of delivery: permanent changes in intestinal flora after Cesarean delivery. J Pediatr Gastroenterol Nutr 1999;28:19-25.

3 Kalliomäki M, Kirjavainen P, Eerola E, et al. Distinct patterns of neonatal gut microflora in infants developing or not developing atopy. $J$ Allergy Clin Immunol 2001;107:129-34.

4 Kero J, Gissler M, Grönlund MM, et al. Mode of delivery and asthma-is there a connection? Pediatr Res 2002; 52:6-11.

5 Kirjavainen PV, Arvola T, Salminen SJ, et al. Aberrant composition of gut microbiota of allergic infants: a target of bifidobacterial therapy at weaning? Gut 2002;51:51-5.

\section{Crohn's ileitis after liver transplantation from a living related donor with Crohn's disease}

We read with interest the case described by Sonwalkar et al of a patient who developed fulminant Crohn's colitis after allogeneic stem cell transplantation (ASCT) (Gut 2003;52:1518-21). Although the donor had no known Crohn's disease (CD) and did not carry the IBD3 or IBD5 haplotypes associated with CD, HLA class III mismatches at IBD3 and a CD associated polymorphism of the 5'UTR of NOD2/CARD15 were present in the donor and in the reconstituted immune cell population of the recipient post ASCT. The authors hypothesised that adoptive transfer of CD susceptibility may have occurred between ACST donor and recipient.

Herein, we report a case of a patient who developed CD after receiving a living related liver transplant from a donor with known CD. A 24 year old female received a liver transplant from a living related donor for decompensated cirrhosis secondary to vertically transmitted chronic hepatitis C infection. The family history was significant for a

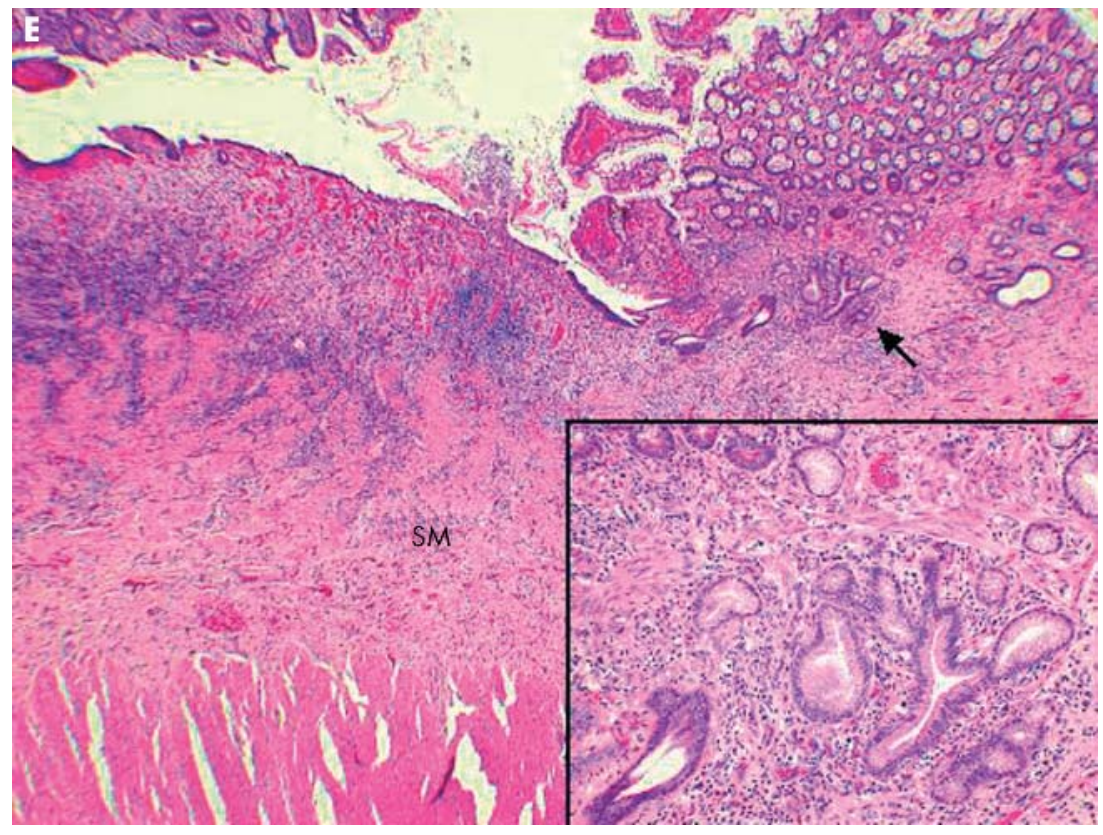

Figure 1 Histopathological examination of a resected ileal specimen demonstrated focal villous blunting, expansion of the lamina propria with acute and chronic inflammatory cells, reactive crypt changes, and occasional crypt abscesses and focal gastric metaplasia (arrow and insert). SM, submucosa.

maternal aunt diagnosed with $\mathrm{CD}$, who served as the liver donor, and a maternal uncle and grandfather with colon cancer. Following liver transplantation, the patient was maintained on an immunosuppressive regimen consisting of tacrolimus $3 \mathrm{mg}$ twice daily, sirolimus $5 \mathrm{mg}$ daily, as well as TMPSMZ prophylaxis. Her initial post-transplant course was uneventful but she later developed recurrent hepatitis C infection, treated with pegylated interferon and ribavirin. She presented with symptoms consistent with intermittent small bowel obstruction 11 months post-transplant. She was also receiving prednisone $15 \mathrm{mg}$ daily at that time. A computed tomography scan of the abdomen and pelvis (see fig lA on the Gut website: www.gutjnl.com) and an upper gastrointestinal with small bowel follow through study (see fig 1B on the Gut website: www.gutjnl.com) demonstrated marked fold thickening of the distal ileum. An enteroscopy demonstrated patchy ulcerations in the jejunum and Roux-en-Y limb of the small bowel. Biopsies showed focal ulceration and mild active inflammation without evidence of granuloma or viral inclusions. Wireless capsule endoscopy demonstrated multiple erosive and ulcerative changes in the distal small intestine (see fig IC, ID on the Gut website: www.gutjnl.com).

Because of persistent symptoms and concern for possible lymphoproliferative disorder, the patient underwent an open laparoscopy which revealed nodularity of the terminal ileum. Intraoperative colonoscopy demonstrated nodularity and three ulcers in the distal ileum. Histopathological examination of the resected ileal specimen demonstrated focal villous blunting, expansion of the lamina propria with acute and chronic inflammatory cells, reactive crypt changes, and occasional crypt abscesses and focal gastric metaplasia (see fig $\mathrm{lE}$, arrow and insert below). Mucosal ulcerations were underlined by inflamed granulation tissue containing occasional histiocytes and multinucleated giant cells. The submucosa also showed intense fibrosis and hyperplasia of the nerve bundles (not shown).

Few cases of de novo IBD developing after liver transplantation for chronic liver disease other than primary sclerosing cholangitis have been described. ${ }^{1-4}$ We present a case of $\mathrm{CD}$ developing in the recipient of a liver transplant from a living related donor with a known history of $\mathrm{CD}$. The recipient tested negative for any of the three common $C D$ associated NOD2/CARD15 variants (R702W, G908R, 1007fsinsC) but unfortunately we were unable to screen the liver donor for these polymorphisms. Our case, similar to that described by Sonwalkar et al, raises the intriguing possibility that $\mathrm{CD}$ susceptibility may have been transferred to the recipient with liver transplantation as well. Collins et a have reported complete and stable replacement of recipient haematopoiesis and $\mathrm{B}$ lymphopoiesis with donor derived cells approximately six weeks following orthotopic liver transplantation for haemochromatosis. $\mathrm{T}$ lineage reconstitution also occurred and derived almost exclusively from expansion of mature memory/effector $\mathrm{T}$ cells from the transplanted liver. One possibility is that the expanded immune cells have become tolerant to the graft but not to the intestinal luminal antigens leading to the development of CD. Whether liver donor selection should exclude those with a known diagnosis of $\mathrm{CD}$ is unclear and is still premature to answer.

K A Papadakis, R Matuk, M T Abreu, E A Vasiliauskas, P R Fleshner, J Lechago, T Tran, F F Poordad, P Martin, J Vierling, S R Targan

Cedars-Sinai Medical Center, UCLA School of Medicine, Los Angeles, California, USA 

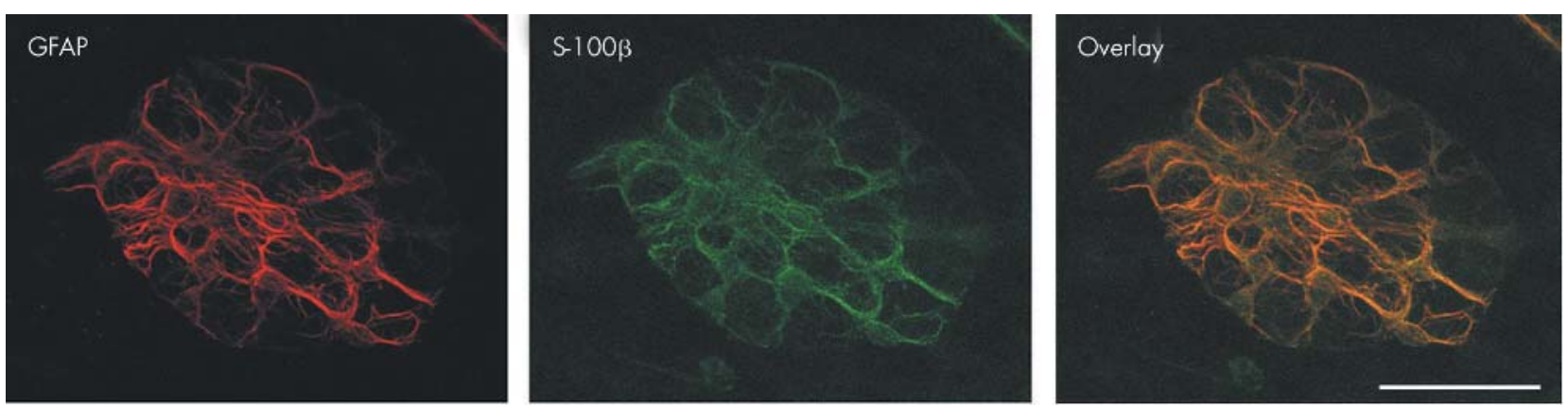

Figure 1 Confocal image revealing colocalisation of glial fibrillary acidic protein (GFAP) and S-100 in enteric glia.

Correspondence to: Dr K A Papadakis, Cedars-Sinai Medical Center, UCLA School of Medicine, 8700 Beverly Blvd, D-4063 Los Angeles, California 90048 , USA; Papadakisk@cshs.org

\section{References}

1 Passfall J, Distler A, Riecken EO, et al. Development of ulcerative colitis under the immunosuppressive effect of cyclosporine. Clin Invest 1992;70:611-13.

2 Riley TR, Schoen RE, Lee RG, et al. A case series of transplant recipients who despite immunosuppression developed inflammatory bowel disease. Am J Gastroenterol 1997:92:279-82.

3 Cuoco L, Tursi A, Cammarota G, et al. Onset of ulcerative colitis during immunosuppressive therapy for liver transplantation. Am $J$ Gastroenterol 1997;92:2134-5.

4 Ramii A, Owen DA, Erb SR, et al. Post-liver transplant Crohn's disease: graft tolerance but not self-tolerance? Digest Dis Sci 2002;47:522-7.

5 Collins RH jr, Sackler M, Pitcher CJ, et al. Immune reconstitution with donor-derived memory/ effector T cells after orthotopic liver transplantation. Exp Hematol 1997;25: 147-59.

\section{Enteric glia}

von Boyen et al recently reported a study of glial fibrillary acidic protein (GFAP) expression in enteric glia (Gut 2004;53;222-8). Their new data are very interesting and add to our understanding of the possible role of enteric glia in gastrointestinal pathophysiology. However, we must take issue with some of the data presented that show extensive nuclear labelling with S-100 and with the description of the distribution of enteric glia in the colon.

Figure 1 of their paper shows labelling of enteric glia in the rat colon below the epithelial crypts and is thus presumably labelling of cells in the submucosal plexus. In the paper, this layer is described as the "plexus mucosus". The plexus mucosus, which is also known as the mucosal plexus, ${ }^{1}$ has previously been described in humans and rat. $^{23}$ As the name implies, the mucosal plexus is located within the mucosa. Given the position of the crypts, as indicated by the ovals in fig 1 , it would appear that the labelling shown in panels $A$ and $B$ is in fact localised to the submucosal plexus.

We find extensive colocalisation of GFAP and S-100 in the submucosal plexus. This is illustrated below in fig 1 in a whole mount preparation of the submucosal plexus from the rat colon. This confocal image reveals colocalisation of GFAP and S-100 in enteric glia ( $17 \mu \mathrm{m} \mathrm{z}$ stack of $1 \mu \mathrm{m}$ optical sections; scale bar $50 \mu \mathrm{m}$ ) (fig 1). S-100 is also found in the cytoplasm of the glial perikarya; there is virtually no nuclear labelling, which was the most obvious element of the staining demonstrated by von Boyen et al.

In fig 1 of the paper of von Boyen et al, the nature of the GFAP immunoreactivity is not fibrous, but granular, while the predominant labelling of S-100 is nuclear. In our hands this is not the case (see our fig 1) and so we feel this calls into question whether the extensive nuclear labelling observed in both fig 1 and fig 2 is really reflective of the distribution of S-100. Moreover, in the paper cited by the authors in support of nuclear localisation, Ferri et al state that "only cytoplasmic localisation (of S-100) was consistently demonstrated in enteric glia", ${ }^{4}$ contrary to von Boyen et al's assertion that S-100 labelling is largely nuclear.

Finally, it should also be noted that GFAP expression in culture may reflect an altered state of differentiation as an adaptation to culturing. ${ }^{56}$ Hence some of the observed changes in GFAP expression may be explained by processes reflecting changes in the culture conditions rather than a pathophysiological response to cytokines.

The issues of glial heterogeneity and the role of enteric glia in inflammation raised in the paper are very interesting, and of considerable importance in understanding the physiology and pathophysiology of the gastrointestinal tract. By analogy with the brain, it is likely that enteric glia play an important role in the function of the gut. However, we feel that the extensive glial heterogeneity suggested in the paper by von Boyen et al may be overestimated and we urge caution in extrapolation of these data based on the immunohistochemistry presented in this manuscript.

K A Sharkey, Y Nasser Gastrointestinal Research Group, Department of Physiology and Biophysics, University of Calgary, Calgary, Alberta, Canada

A Ruhl

Department of Human Biology, Technical University Munich, Freising-Weihenstephan, Germany

Correspondence to: Professor K A Sharkey, Gastrointestinal Research Group, Department of Physiology and Biophysics, University of Calgary, 3330 Hospital Drive, NW Calgary, Alberta, Canada T2N 4N1; ksharkey@ucalgary.ca

\section{References}

Furness JB, Costa M. The enteric nervous system. Edinburgh: Churchill-Livingstone, 1987.

2 Wedel T, Roblick U, Gleiss J, et al. Organization of the enteric nervous system in the human colon demonstrated by wholemount immunohistochemistry with special reference to the submucous plexus. Anat Anz 1999; 181:327-37.

3 Stach W. Innervation of the small intestinal mucosa of laboratory animals. II. Ultrastructure of neuro-cellular connections. Z Mikrosk Anat Forsch 1979:93:1012-24.

4 Ferri GL, Probert L, Cocchia D, et al. Evidence for the presence of S-100 protein in the glial component of the human enteric nervous system. Nature 1982;297:409-10.

5 Juurlink BH, Hertz L. Plasticity of astrocytes in primary cultures: an experimental tool and a reason for methodological caution. Dev Neurosci 1985;7:263-77.

6 Hauck SM, Suppmann S, Ueffing M. Proteomic profiling of primary retinal Müller glia cells reveals a shift in expression patterns upon adaptation to in vitro conditions. Glia 2003;44:251-63.

\section{CORRECTIONS}

doi: 10.1136/gut.2003.021154corrl

In the paper by Wang et al (Gut 2004;53:1096-1101), the acknowledgement and correct email address were not presented. The acknowledgement should have read as follows: "The authors thank senior technician Shu-Hao Wen for her assistance in processing the tissue slides, and Drs Jian-Ming Qian, Gang Sun, and Xiao-Hong Liu for their help in collecting the biopsy samples for the study project." In addition, the correct email address for Professor G-Z Pan is: pgz@public3.bta.net.cn.

\section{doi: 10.1136/gut.2003.027425corr 1}

An author was omitted from the paper by Francés et al (Gut 2004;53:860-4), entitled Bacterial DNA activates cell mediated immune response and nitric oxide overproduction in peritoneal macrophages from patients with cirrhosis and ascites. This paper was published in the June issue and the missing author is E Rodriguez, Immunology Department, Hospital General Universitario, Alicante, Spain. 